Research article

urn:1sid:zoobank.org:pub:B05B3C54-31C8-42C4-940F-63354D573678

\title{
Three new Neotropical species and a new genus of land flatworms (Platyhelminthes, Geoplaninae)
}

\author{
Karine Gobetti de OLIVEIRA ${ }^{1}$, Laura Bianco BOLONHEZI ${ }^{2}$, Ana Laura ALMEIDA ${ }^{3}$, \\ Domingo LAGO-BARCIA ${ }^{4} \&$ Fernando CARBAYO ${ }^{5, *}$ \\ 1,2,3,4,5 Laboratório de Ecologia e Evolução, Escola de Artes, Ciências e Humanidades, Universidade de \\ São Paulo-USP, Av. Arlindo Bettio, 1000, CEP 03828-000, São Paulo, SP, Brazil. \\ 3,5 Museu de Zoologia da Universidade de São Paulo, Avenida Nazaré, 481, \\ CEP 04263-000, Ipiranga, São Paulo, SP, Brazil. \\ ${ }^{4,5}$ Departamento de Zoologia, Instituto de Biociências, Universidade de São Paulo, \\ Rua do Matão, Trav. 14, 321, Cidade Universitária, CEP 05508-900, São Paulo, SP, Brazil.
}

*Corresponding author: baz@usp.br

${ }^{1}$ Email: karine.gobetti.oliveira@usp.br

${ }^{2}$ Email: laura.bolonhezi@usp.br

32Email: ana.laura.santos@usp.br

${ }^{4}$ Email: domingo.lagobarcia@gmail.com

${ }^{1}$ urn:Isid:zoobank.org:author:CABFB5FD-2E07-4887-9EEE-99646C3AAD4F
${ }^{2}$ urn:lsid:zoobank.org:author:3A754EE2-FDE5-4D88-BE81-619ED5AAC491
${ }^{3}$ urn:lsid:zoobank.org:author:DA8396A4-2113-47C7-8EA5-41B9651BEE32
${ }^{4}$ urn:Isid:zoobank.org:author:1C988356-F43C-4ACC-B137-3CAA3BBC23B1
${ }^{5}$ urn:lsid:zoobank.org:author:FEFD8A85-5041-4F95-9F0F-FC12ADE0B29E

Abstract. Three new Neotropical land planarians (Platyhelminthes, Tricladida, Geoplaninae) from the Brazilian Atlantic forest are described. Obama apiguara Oliveira, Almeida \& Carbayo sp. nov. presents glandular fossae opening through dorsal epithelium, a structure not documented previously among land flatworms. Paraba tata Bolonhezi, Lago-Barcia \& Carbayo sp. nov., is characterized by a prostatic vesicle horizontal with an inconspicuous bifurcate portion, a penis papilla as long as male atrium and a female genital duct projected from the postero-dorsal section of the female atrium. The third new species is distinctive in the extraordinarily thick muscle surrounding the prostatic vesicle, a finger-shaped penis papilla, and a dilated female genital cavity. These attributes stands the species apart from all members of Geoplaninae and Piima ata Carbayo gen. et sp. nov. is proposed.

Keywords. Planarians, Geoplanidae, Obama, Paraba, Piima Carbayo gen. nov., glandular fossae.

de Oliveira K.G., Bolonhezi L.B., Almeida A.L., Lago-Barcia D. \& Carbayo F. 2020. Three new Neotropical species and a new genus of land flatworms (Platyhelminthes, Geoplaninae). European Journal of Taxonomy 705: 1-21. https://doi.org/10.5852/ejt.2020.705 


\section{Introduction}

Land planarians (Platyhelminthes Gegenbaur, 1859, Tricladida Lang, 1884, Geoplanidae Stimpson, 1857) are richly diversified in the Brazilian Atlantic forest (Sluys 1999). Most species in this biome belong to the exclusively Neotropical subfamily Geoplaninae Stimpson, 1857, with 25 genera plus the collective genus Pseudogeoplana Ogren \& Kawakatsu, 1990. This genus houses species of Geoplaninae, whose internal morphology remains unknown, particularly that of the copulatory apparatus. This organ is the main morphological character used in planarian taxonomy. Currently, the subfamily encompasses 332 species (Carbayo 2019).

Over the last ten years, we have been conducting intense sampling for these organisms across the south and southeast portions of the Atlantic forest from the state of Espírito Santo to Rio Grande do Sul. As part of the samplings, we collected representatives of three unknown species. One of the species is a member of Obama Carbayo et al., 2013, another species belong to Paraba Carbayo et al., 2013 and the third species is placed in a new genus herein proposed.

\section{Material and methods}

Specimens were found through a visual search on the soil litter in the forest during the day and night. We took pictures of them, and killed them in boiling water. We fixed the remaining part of the body in $10 \%$ formalin or $80 \%$ ethanol and, subsequently, transferred it to $80 \%$ ethanol. The body was cut into portions

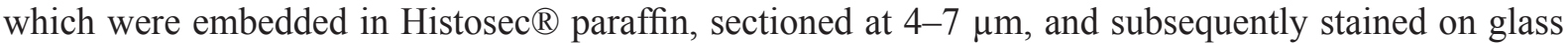
slides with the Mallory method as modified by Cason (1950). We examined the sections and reconstructed the copulatory apparatuses and pharynges with a compound microscope and a camera lucida attached. We took digital photomicrographs with the help of a digital camera Olympus DP72 attached to the microscope. We enhanced the contrast of the photomicrographs and provided a whitish background with GIMP (GNU Image Manipulation Program vers. 2.8.16; the GIMP Team www.gimp.org, 1995-2016). We orientated the drawings and the photomicrographs of sagittal and horizontal views with the anterior body region to the left.

Specimens examined in this study were deposited in MZUSP $=$ Museu de Zoologia da Universidade de São Paulo.

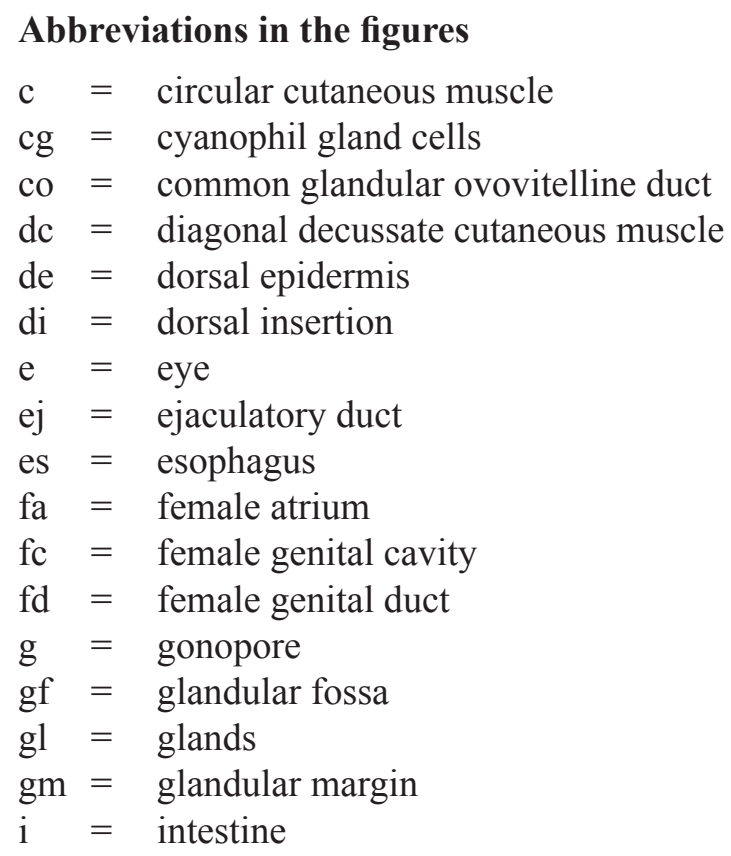




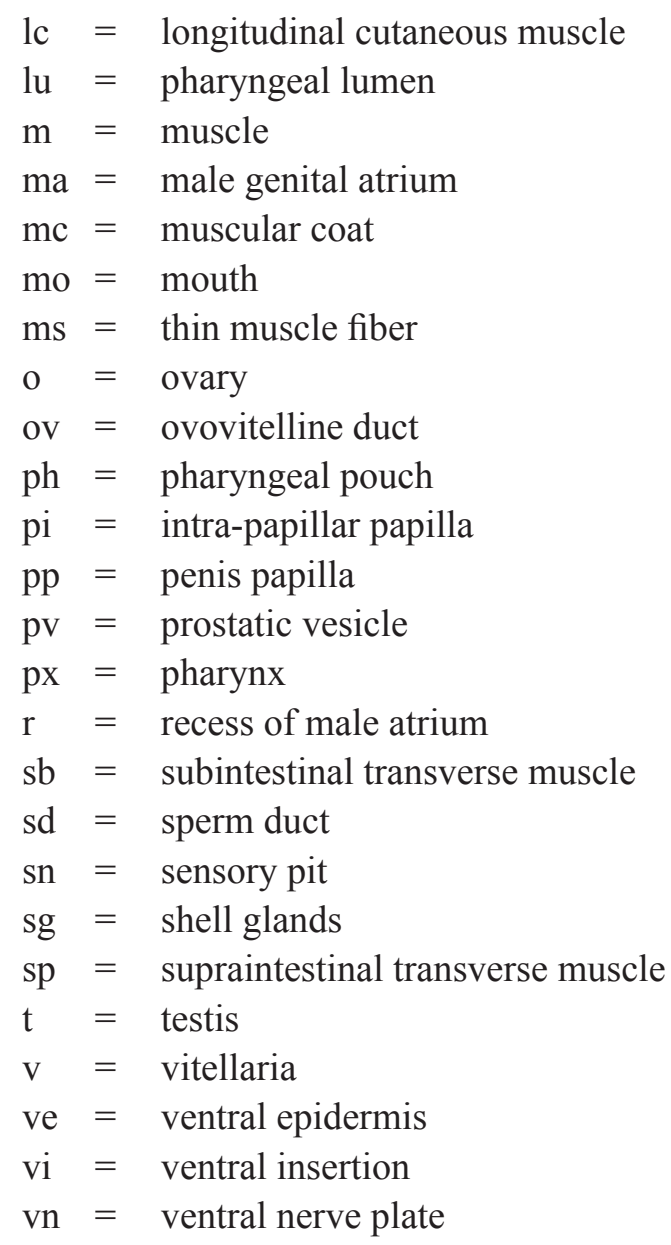

\section{Results}

Order Tricladida Lang, 1884

Suborder Continenticola Carranza, Littlewood, Clough, Ruiz-Trillo, Baguñà \& Riutort, 1998

Family Geoplanidae Stimpson, 1857

Genus Obama Carbayo, Álvarez-Presas, Olivares, Marques, Froehlich \& Riutort, 2013

Obama apiguara Oliveira, Almeida \& Carbayo sp. nov. urn:1sid:zoobank.org:act:CBCCCD96-212C-4958-AE86-7CB5AE6E1653

Figs $1-5$

\section{Diagnosis}

A species of Obama with a dark ivory dorsum, dark tips and numerous small longitudinal black striae and a glandular fossae opening through the epidermic epithelium. The subintestinal parenchymal muscle is intermingled with the nerve plexus. The penis papilla is provided with a small intra-papillar, fingerlike papilla. A common glandular ovovitelline duct is absent. The female genital duct projects from the mid-dorsal section of the female atrium.

\section{Etymology}

The name, 'apiguara' (apyguara) is a Tupi (indigenous Brazilian language) word, meaning 'nasal fossae' (Bueno 1998). It refers to the glandular fossae opening through the epidermis. 


\section{Material examined}

Holotype

BRAZIL - 1 adult; State of Santa Catarina, Três Barras, Parque Nacional de São Joaquim; $28.2356^{\circ}$ S, $49.4988^{\circ}$ W; 6 Sep. 2017; F. Carbayo et al. leg.; sagittal sections of copulatory apparatus on 54 slides, transverse sections of cephalic region on 26 slides, horizontal sections of portion containing ovaries on 11 slides, sagittal sections of posterior portion containing ovaries on 23 slides, sagittal sections of pharynx region on 32 slides, transverse sections of pre-pharyngeal region on 11 slides; field number F7378; MZUSP PL2187.

\section{Type locality}

Três Barras (Parque Nacional de São Joaquim), state of Santa Catarina, Brazil.

\section{Description}

MeAsurements. The holotype, preserved, is $56 \mathrm{~mm}$ long and $8 \mathrm{~mm}$ wide.

BoDy. Broad and flattened dorsoventrally. The body margins are nearly parallel, except the anterior $25 \%$, and the posterior $17 \%$ of the body, which are pointed and obtuse, respectively. The dorsum is slightly convex, the ventral side flat. The color of the dorsum of the living specimen is dark ivory, pigmented and with numerous small longitudinal black striae formed by small spots. The anterior and posterior extremities, each $10-15 \%$ of body length, exhibit a black pigment. This pigment almost covers the striae (Fig. 1A). The ventral side is pastel-yellow in color, whitish in the region of the pharynx and the copulatory apparatus, and brown in both extremities (17\% of the length of the body) (Fig. 1B).

EyEs. Single-lobed and without halos, measuring about $50 \mu \mathrm{m}$ in diameter. They are absent at the very anterior apex of the body (Fig. 2A) and are initially uniserial. Behind $4 \mathrm{~mm}$ ( $7 \%$ of body length from anterior tip), they are arranged in 2-3 marginal rows, which reach, on each side, approximately $0.7 \mathrm{~mm}$ of the total body width (1.25\% of the body width). The eye distribution reaches the region of the gonopore, behind it becoming scarcer until the posterior tip of the body. The sensory pits are about $45 \mu \mathrm{m}$ deep, and are distributed in a single ventro-marginal row. They contour the anterior extremity of the body and are distributed along the body until $14 \mathrm{~mm}$ from anterior extremity ( $25 \%$ of body length).

CREePING SOLE. Occupies approximately $96 \%$ of the body width. The positions of the mouth and the gonopore relative to the anterior tip are about $70 \%$ and $85 \%$ of the body length, respectively. In the prepharyngeal region (Fig. 2B), the dorsal epithelium is crossed by necks of rabditogen cells, especially on the sides of the body; it is also crossed by necks of cells producing fine $(1.2 \mu \mathrm{m})$ cyanophil granules and by necks of scarce cells producing xanthophil and erythrophil granules, respectively. The ventral epithelium is traversed by an abundant number of necks of cells producing cyanophil granules and a low number of necks of cells producing either xanthophil or erythrophil fine granules. In the body margins, the density of gland cells slightly increases giving rise to a poorly delimited glandular margin (Fig. 2B).

ANTERIOR 45\% OF THE BODY. Presents a structures herein called glandular fossae. These glandular fossae are distributed irregularly in a simple or double row along the dorsal and body margins (Fig. 3). A few fossae are also found in the ventral body margins (Fig. 3E). A glandular fossa consists of a 30-70 $\mu \mathrm{m}$ deep invagination, mostly simple (Fig. 3C), sometimes bifurcate (Fig. 3D). The invaginations are lined with a $5-15 \mu \mathrm{m}$ high epithelium, that is lower than surrounding body epithelium ( $25 \mu \mathrm{m}$ high). Cells of the lining epithelium are strongly erythrophil. The lumen of the fossae seem to contain red-pinkish threads and fine erythrophil granules. Necks of glands producing xanthophil secretions are located in surrounding parenchyma of the fossae, but they apparently do not discharge their secretion into the fossae but through surrounding epidermal cells. 


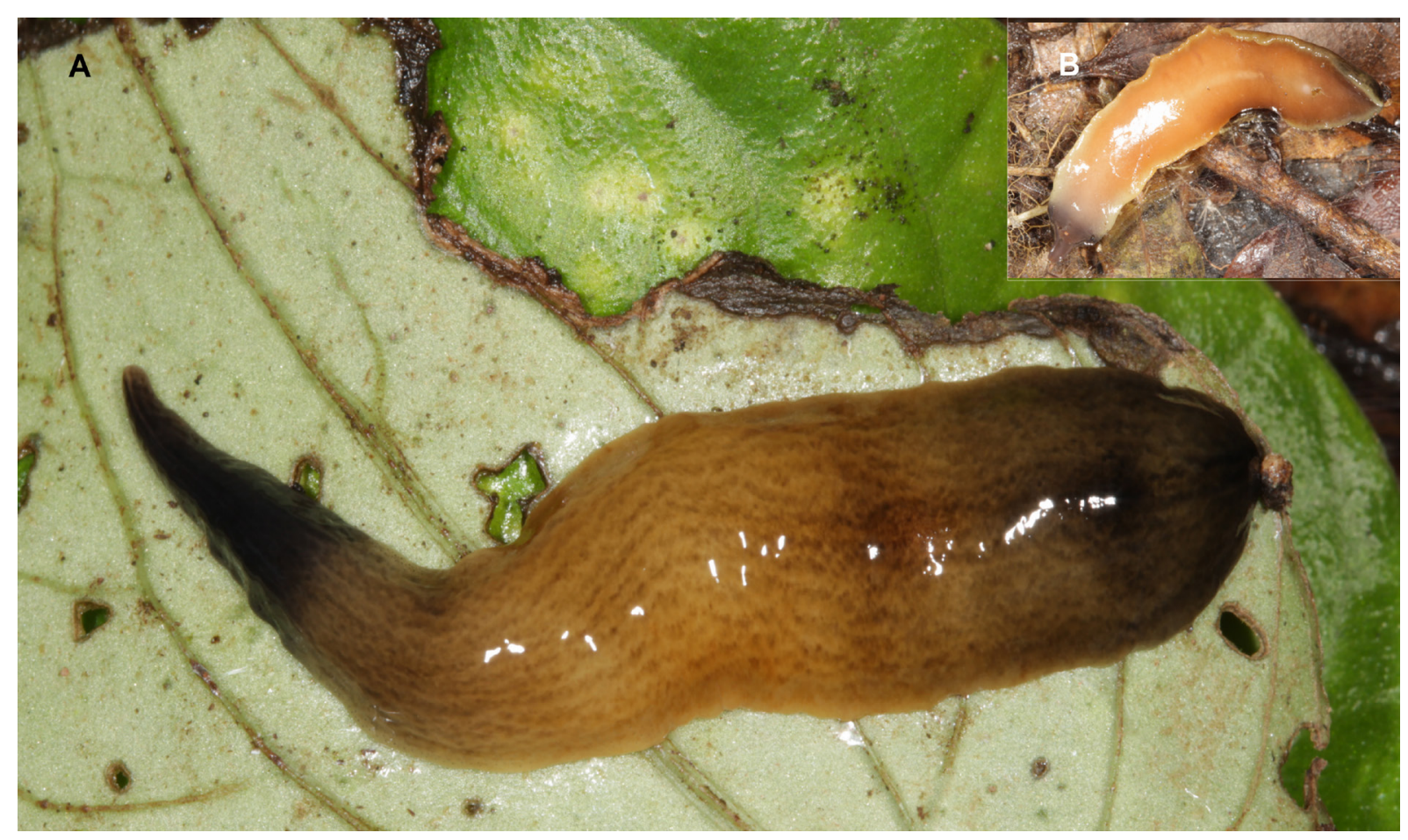

Fig. 1. Obama apiguara Oliveira, Almeida \& Carbayo sp. nov., living holotype (MZUSP PL2187), $56 \mathrm{~mm}$ in length. A. Dorsal view. B. Ventral view.
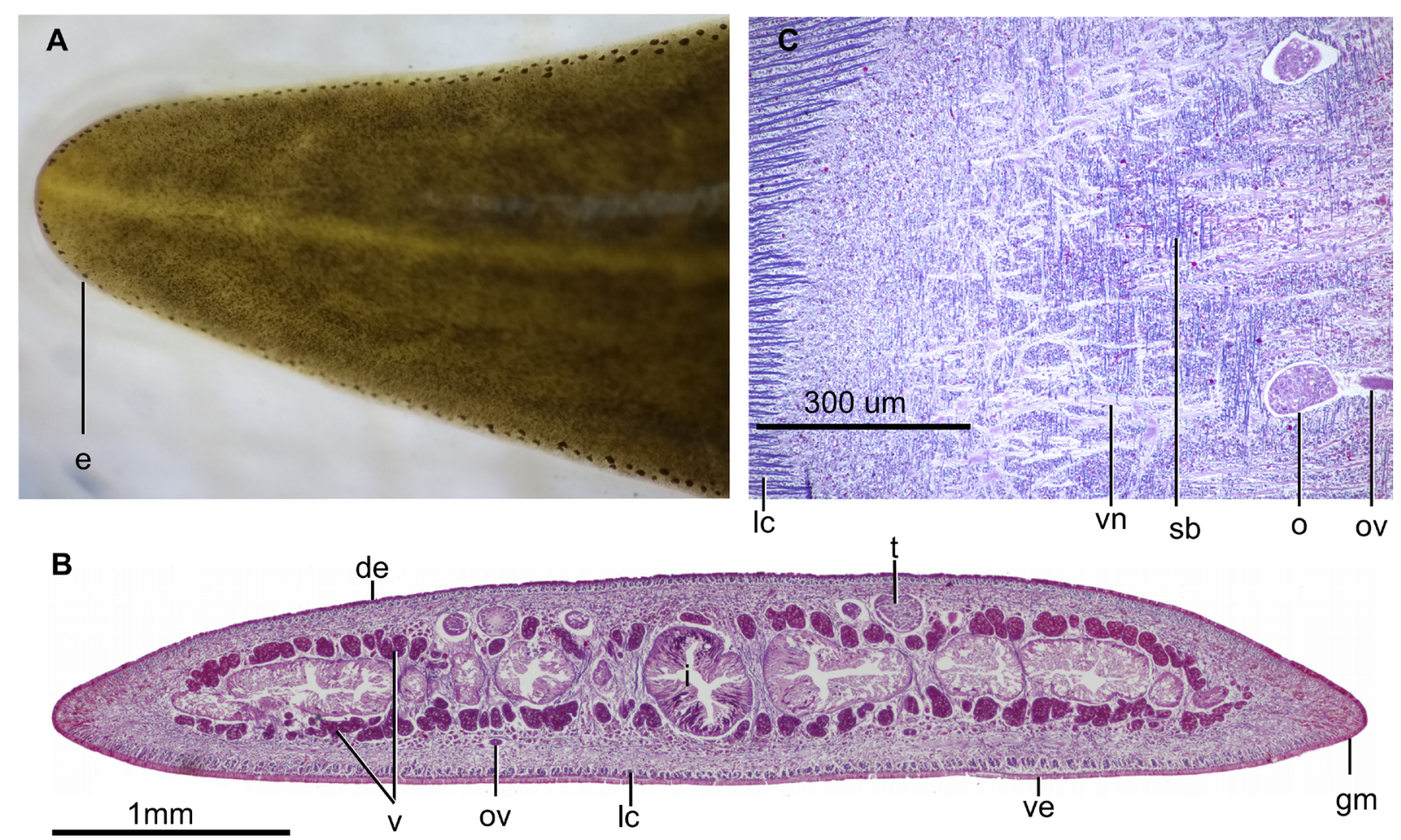

Fig. 2. Obama apiguara Oliveira, Almeida \& Carbayo sp. nov., holotype (MZUSP PL2187). A. Anterior extremity in clove oil. B. Photomicrograph of horizontal section showing ovaries and musculature. C. Photomicrograph of transverse section of pre-pharyngeal region. 
Cutaneous musculature. Organized in three layers: a subepithelial layer of circular fibers, followed by a layer of double diagonal fibers and a longitudinal one with bundles composed of 32-96 fibers each. The thickness of the cutaneous musculature is $10 \%$ of the body height in the pre-pharyngeal region. The parenchymal musculature is composed of a dorsal layer of diagonal fibers, followed by a supraintestinal layer of transverse fibers and a subintestinal layer of transverse fibers extending below the nerve plate, thus intermingled with it. The main nervous system presents the shape of a plate (Fig. 2C).

Mouth. Opens at the end of the second third of the pharyngeal pouch. The pharynx is cylindrical (Fig. 4A), with the dorsal insertion posteriorly shifted. It occupies $77 \%$ of the length of the pharyngeal pouch. An esophagus is present; under its lining epithelium, there is a one-fiber-thick muscle layer followed by a layer $(50 \mu \mathrm{m})$ of circular fibers interspersed with longitudinal fibers. The pharynx is lined with a cuboidal, ciliated epithelium. The pharyngeal epithelium is crossed by necks of three types of gland cells producing erythrophil, cyanophil and xanthophil granules, respectively. The outer pharyngeal epithelium is lined with a longitudinal muscle $(5 \mu \mathrm{m})$, followed by a circular muscle $(5 \mu \mathrm{m})$. The inner pharyngeal epithelium is lined with a a layer $(100 \mu \mathrm{m})$ of circular fibers interspersed with longitudinal fibers, followed by a one-fiber-thick layer of longitudinal fibers.

Testes. Dorsal, with a round shape, the largest being about $300 \mu \mathrm{m}$ in diameter. They are arranged in 3-4 rows on each side of the body, starting $13 \mathrm{~mm}$ behind the anterior extremity of the body and reaching $20.5 \mathrm{~mm}$, which corresponds to $23 \%$ and $37 \%$ of the body length, respectively.
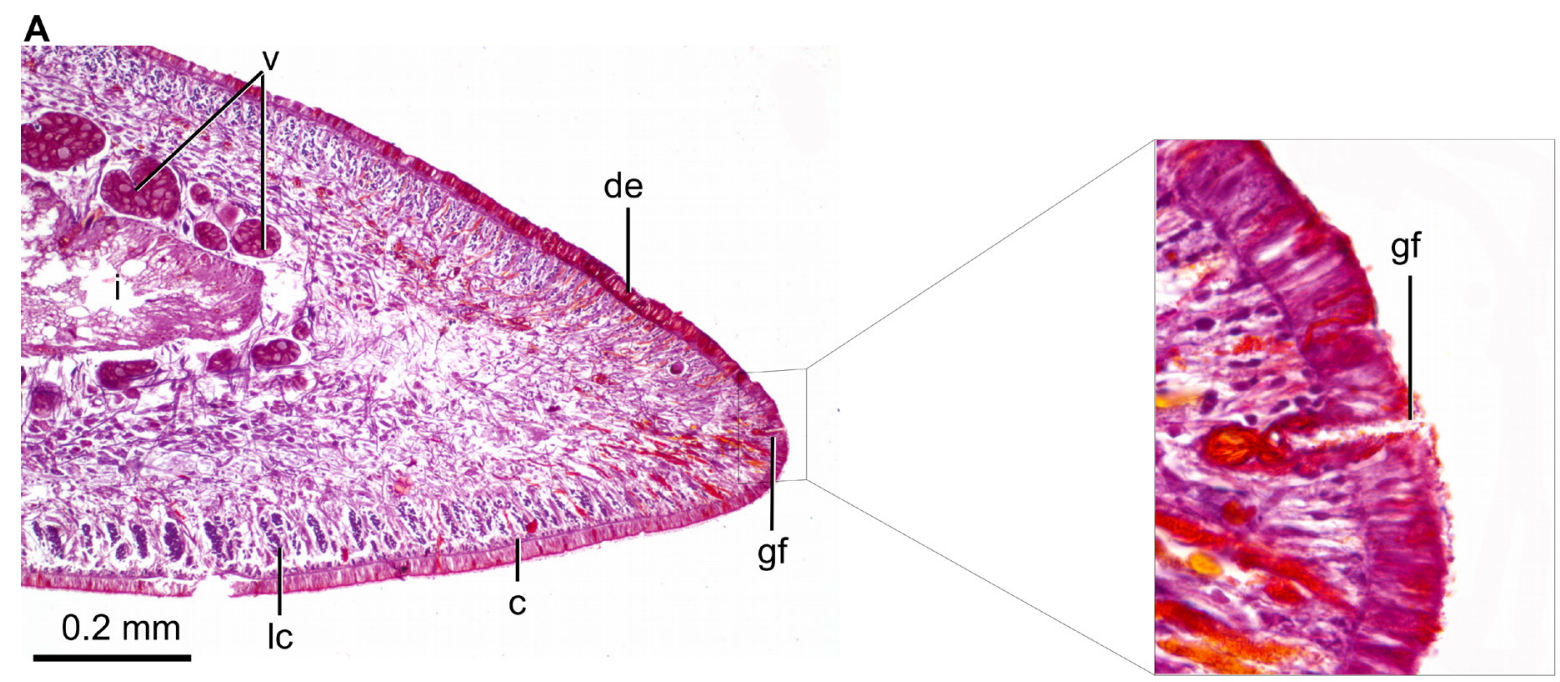

$15 \mathrm{um}$

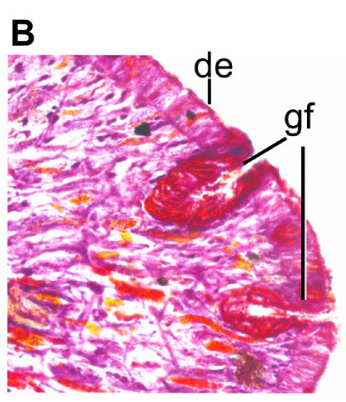

$40 \mathrm{um}$

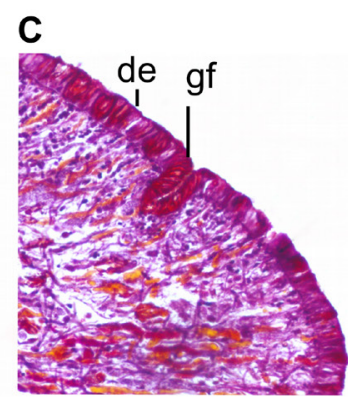

$\underline{60 \mathrm{um}}$

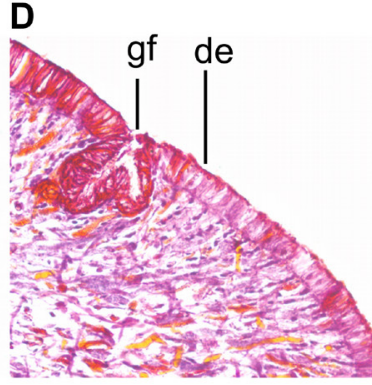

$120 \mathrm{um}$

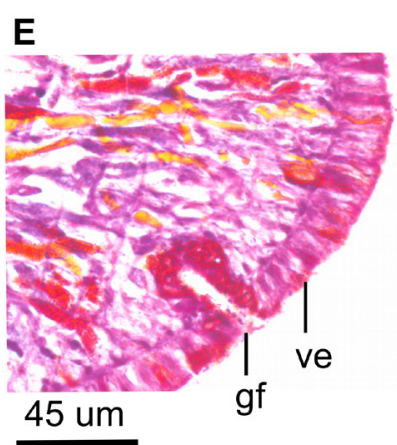

Fig. 3. Obama apiguara Oliveira, Almeida \& Carbayo sp. nov., holotype (MZUSP PL2187). A-E. Photomicrographs of transverse sections of anterior region showing different glandular fossae. 

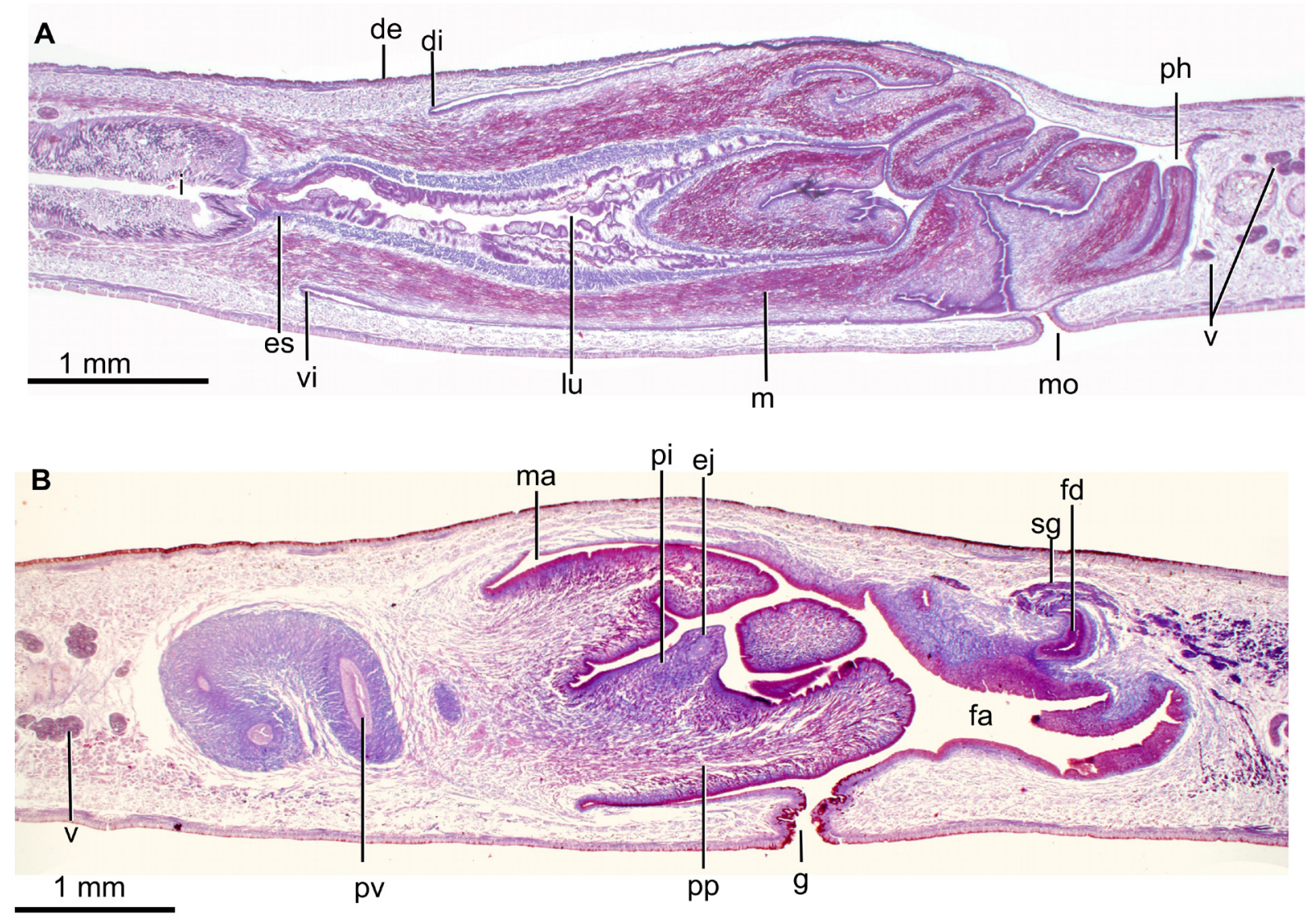

Fig. 4. Obama apiguara Oliveira, Almeida \& Carbayo sp. nov. holotype (MZUSP PL2187). Photomicrographs of sagittal sections of holotype. A. Pharynx. B. Copulatory apparatus.

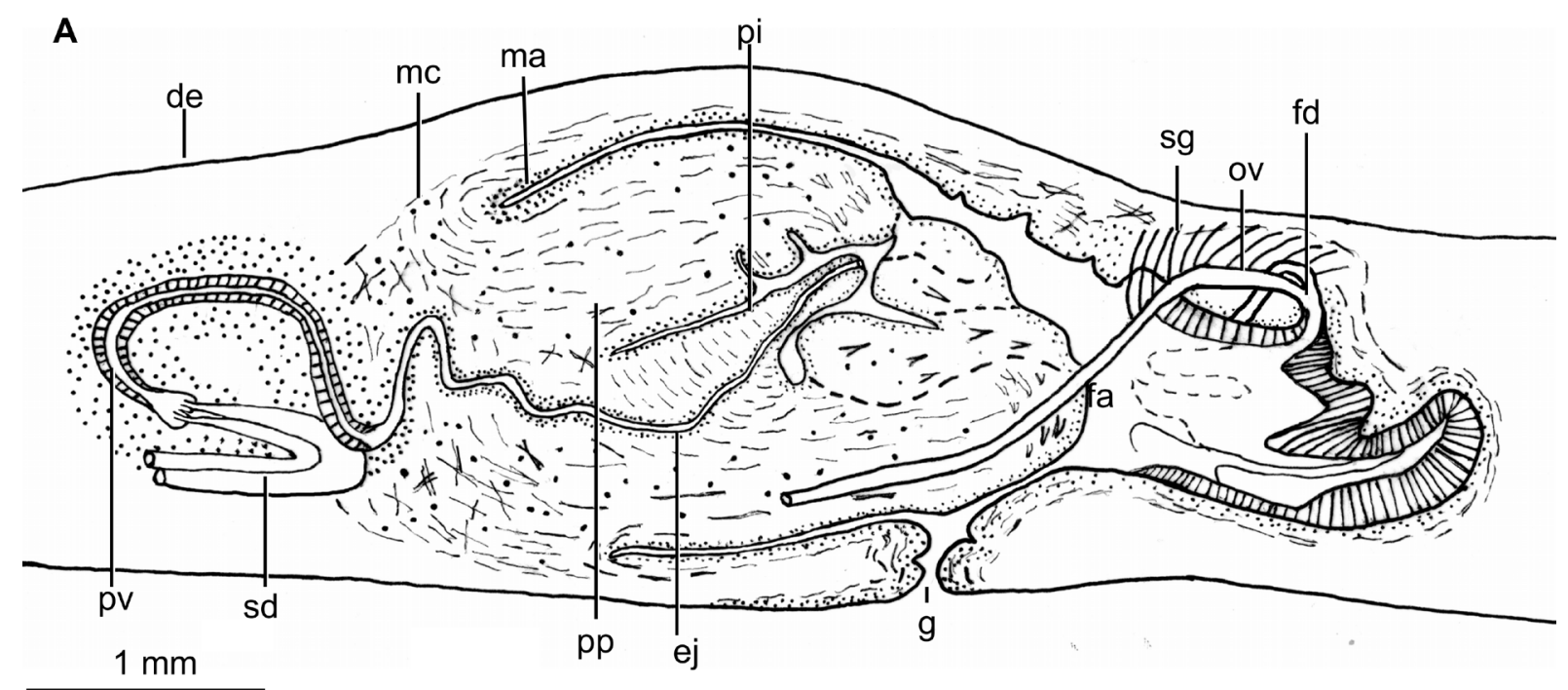

Fig. 5. Obama apiguara. Oliveira, Almeida \& Carbayo sp. nov. holotype (MZUSP PL2187). Diagrammatic representation of the copulatory apparatus from sagittal sections. 
EFFERENT DUCTS. Bend upwards and forwards before ending in the proximal portion of the prostatic vesicle. The prostatic vesicle is extrabulbar, elongate and exhibits an inverted-U shape in lateral view. The proximal portion of this vesicle is forked. The vesicle enters the ventro-anterior section of the penis bulb to communicate with the ejaculatory duct. The prostatic vesicle is lined with a columnar, ciliated epithelium which is crossed by necks of cells producing erythrophil granules. This epithelium is surrounded by a circular muscle (160 $\mu \mathrm{m}$ thick), the ectal fibers of which are decussate.

EJACUlatory DUCT. Meanders in the first half of its length and becomes straight in the second half. This duct crosses the center of the intrapenial papilla, and its lining epithelium is columnar ( $25 \mu \mathrm{m}$ tall) and ciliated. This epithelium is crossed by necks of cells producing erythrophil granules in its first half; in its second half, it is pierced by necks of cells producing cyanophil granules. The epithelium is surrounded by a circular muscle ( $30 \mu \mathrm{m}$ thick).

PeNIS PAPILLA. Larger than the male atrium and cylindrical, with its dorsal insertion slightly anterior to its ventral. It is provided with a finger-like intra-penial papilla with $600 \mu \mathrm{m}$ in length, which is oriented postero-dorsally (Figs 4B, 5). The epithelium of the intra-penial papilla is $5 \mu \mathrm{m}$ high, and crossed by necks of cells producing erythrophil and cyanophil granules, respectively. This epithelium is underlain by a $2 \mu \mathrm{m}$ thick longitudinal muscle, followed by a circular muscle ( $6 \mu \mathrm{m}$ thick). This intra-penial papilla has radial muscle fibers and is provided with a sort of penis bulb constituted by crossed fibers. The large penis papilla is lined with a cuboidal-to-columnar epithelium, which is pierced by necks of abundant cells producing erythrophil granules. This epithelium is underlain by a circular muscle $(15 \mu \mathrm{m}$ thick), followed by a longitudinal muscle (20-30 $\mu \mathrm{m}$ thick), both layers being intermixed close to the insertions of the penis papilla.

Male ATRium. Large and not folded, lined with a squamous-to-cuboidal epithelium, which is crossed by necks of cells producing erythrophil granules and a low number of necks of cells producing xanthophil granules. This epithelium is underlain by a circular muscle (17.5 $\mu \mathrm{m}$ thick), which in some areas presents intermingled longitudinal fibers.

Ovaries (Fig. 2C). Ovoid, $550 \mu \mathrm{m}$ in length and $300 \mu \mathrm{m}$ in width, approximately. They are situated at a distance from the anterior extremity of the body, equivalent to $27 \%$ of the body length. The ovovitelline ducts emerge from the dorso-lateral region of the ovaries and subsequently run above the nerve plate, ventrally to the efferent ducts. At the level of the gonopore, the ovovitelline ducts bend dorsally to join the female genital duct, which is a projection of the dorso-medial wall of this atrium (Fig. 5). There is no common glandular ovovitelline duct. The distal portion of the ovovitelline ducts receives secretions from the shell glands. The female genital duct is lined with a $75 \mu \mathrm{m}$ high, non ciliated epithelium. This epithelium is crossed by necks of two types of cells producing erythrophil and cyanophil granules, respectively.

Female Atrium. Large and as long as the male atrium. The anterior portion of the atrium does not narrow and continues with the male atrium (Figs 4B, 5). The female atrium exhibits 2-3 lateral folds that partially occupy its lumen. It is lined with a non-ciliated epithelium, with a stratified appearance in its posterior region. Towards the anterior portion of the atrium, this epithelium passes progressively to cuboidal (30 $\mu \mathrm{m}$ high, ventrally) or columnar (75 $\mu \mathrm{m}$ high, dorsally), and is crossed by necks of cells producing erythrophil granules and by a low number of necks of cells producing coarse cyanophil granules. The posteriormost section of the female atrium is pierced by cells producing a xanthophil amorphous secretion. The epithelium of the atrium is underlain by a longitudinal muscle ( $8 \mu \mathrm{m}$ thick), followed by a circular muscle; fibers of both muscles are intermingled in some parts. 


\section{Remarks}

This new species best matches Obama, since it presents the diagnostic features of this genus, with the exception of the eyes, which are only monolobate, the small intra-papillar finger-like penis papilla, and the female genital duct projecting from the dorsal side of the female atrium.

Among the 39 members of Obama, only four species also display a similar dorsal color pattern consisting of longitudinal dark small dots on a light ground color, namely O. allandra Marques et al., 2018, O. nungara Carbayo et al., 2015, O. maculipunctata Rossi et al., 2015 and O. marmorata (Schultze \& Müller, 1857). Among them the striae in $O$. marmorata and $O$. nungara only form irregular longitudinal stripes as in the new species. However, in O. nungara, the irregular stripes are wider and the ground color is darker. Obama marmorata is very similar to the new species. Differences are related to the stripes, which are more evident in $O$. marmorata, and to the darker anterior and posterior body tips, restricted to a short body portion in $O$. marmorata.

Among the species of Pseudogeoplana, only Ps. blanchardi (Graff, 1899) and Ps. doederleine (Shirch, 1929) somewhat resemble our species in the marbled aspect of the dorsum. However, in Ps. blanchardi, from Venezuela, the dark spots are rounded (vs striated in O. apiguara sp. nov.); in Ps. doederleine, from Rio Doce (Rio de Janeiro), the spots are absent in a midband which is ornamented with four brownish thin longitudinal stripes (vs absent in Obama apiguara sp. nov.).

Regarding internal morphology, the copulatory apparatus of Obama apiguara sp. nov. resembles that of O. applanata (Graff, 1899) and O. carrierei (sensu Marcus, 1951) in that the latter species present a structure similar to an intra-penial papilla as in the new species (see Marcus 1951: fig. 169; Froehlich 1956: fig. 2). However, $O$. applanata and $O$. carreirei differ from the new species in the following aspects: they a) present the dorsal insertion of the penis papilla shifted posteriorly (vs anteriorly in the new species); b) possess a common glandular ovovitelline duct (vs absent in Obama apiguara sp. nov.); and c) their female genital duct projects from the posterior (O. carreirei) or postero-dorsal aspect (O. applanata) of the female atrium (vs dorsal). In addition, to the best of our knowledge, the new species is the only land planarian having glandular fossae opening through epidermis.

\section{Distribution}

Only known from the type locality.

Order Tricladida Lang, 1884

Suborder Continenticola Carranza, Littlewood, Clough, Ruiz-Trillo, Baguñà \& Riutort, 1998

Family Geoplanidae Stimpson, 1857

Genus Paraba Carbayo, Álvarez-Presas, Olivares, Marques, Froehlich \& Riutort, 2013.

Paraba tata Bolonhezi, Lago-Barcia \& Carbayo sp. nov. urn:lsid:zoobank.org:act:4AA601DC-9098-4F79-AB02-716E68EFD30D

Figs 6-9

\section{Diagnosis}

A species of Paraba, with a dark orange-brown dorsum, a median narrow clear grey stripe and orange body margins; the prostatic vesicle horizontal with an inconspicuous bifurcate portion; the copulatory apparatus relatively long; the penis papilla as long as the male atrium; the female genital duct projected from the postero-dorsal section of the female atrium. 


\section{Etymology}

The name 'tata' (tatá) is a Tupi (indigenous Brazilian language) word meaning 'fire' (Tibiriçá 1984). It refers to the color of the dorsum.

\section{Material examined}

\section{Holotype}

BRAZIL - 1 adult; State of São Paulo, Brazil, Ribeirão Grande, Parque Estadual de Intervales; $24.269387^{\circ} \mathrm{S}, 48.405467^{\circ} \mathrm{W}$; $24 \mathrm{Jul} .2008$; F. Carbayo et al. leg.; transverse sections of cephalic region on 12 slides; horizontal sections of portion behind cephalic region on 7 slides, sagittal sections of pharynx and copulatory apparatus on 9 slides; field number F2637; MZUSP PL2184.

\section{Paratypes}

BRAZIL - 1 adult; same collection data as for holotype; transverse sections of cephalic region on 16 slides, horizontal sections of portion behind cephalic region on 9 slides, sagittal sections of pharynx and copulatory apparatus on 16 slides; field number F3151; MZUSP PL2185 • 1 adult; same collection data as for preceding; transverse sections of cephalic region on 18 slides, horizontal sections of portion behind cephalic region on 8 slides, sagittal sections of pharynx on 22 slides, sagittal sections of copulatory apparatus on 15 slides; field number F3768; MZUSP PL2186.

\section{Type locality}

Parque Estadual de Intervales, Ribeirão Grande, State of São Paulo, Brazil.

\section{Description}

MeAsurements. The preserved paratype F3768 is $22.5 \mathrm{~mm}$ long and $4 \mathrm{~mm}$ wide.

Body. Margins are parallel; the anterior extremity is pointed; the posterior, rounded (Fig. 6A). The dorsum is slightly convex; the ventral side flattened (Fig. 6B). The dorsum is dark orange-brown; the body margins are orange. A narrow clear grey stripe extends along the entire body length, except for the very anterior and posterior body tips. The ventral side is ivory in color.

EYEs. Monolobate and $45 \mu \mathrm{m}$ in diameter. They contour the anterior extremity of the body (Fig. 6C) and are located dorsomarginally along the whole body, except for the very posterior extremity, where they are absent. The sensory pits are $37.5 \mu \mathrm{m}$ deep (F3151) and are arranged in a single row that contours the anterior extremity of the body (Fig. 6D) and behind, they extend backwards to at least a length equal to $18 \%$ of the body length. The relative distance mouth to body length is $74 \%$ and the relative distance of the gonopore is $84 \%$ of the body length.

Through the dorsal epidermis ( $25-30 \mu \mathrm{m}$ thick, F2637), parechymal rhabditogen cells ( $25 \mu \mathrm{m})$ discharge their content, as well as two types of cells producing erythrophil and xanthophil granules, respectively. The epidermis produces rhabdites as well. The ventral epidermis (20-27.5 $\mu \mathrm{m}$ thick, F3151) is ciliated on the creeping sole $(\sim 100 \%$ of body width) only. This epidermis is pierced by necks of abundant cyanophil glands, scarce xanthophil and cyanophil granulous glands and scarce rhabditogen cells. A glandular margin is absent.

Cutaneous musculature. Composed of three layers: a very thin subepithelial circular muscle, followed by a thin diagonal with decussate bundles (both layers with a height of $7.5 \mu \mathrm{m}$ ventraly, dorsally $12.5 \mu \mathrm{m}$ ) and a thick longitudinal muscle (dorsally $87.5 \mu \mathrm{m}$ thick, ventrally $37.5 \mu \mathrm{m}$ ) of fibers arranged in compact bundles (Fig. 6D). The cutaneous musculature thickness relative to body height is $18 \%$. Three parenchymal muscle layers are present: a dorsal layer $(18 \mu \mathrm{m}$ thick $)$ with decussate diagonal 
fibers, a supra-intestinal layer (50 $\mu \mathrm{m}$ thick) with transverse fibers and a sub-intestinal layer (62 $\mu \mathrm{m}$ thick) with transverse fibers.

Mouth. Relative position mouth pharyngeal pouch length is $64 \%$. The pharynx is cylindrical, with its dorsal insertion shifted backwards. A very short esophagus is present, $4 \%$ of the pharynx length (Fig. 7A).
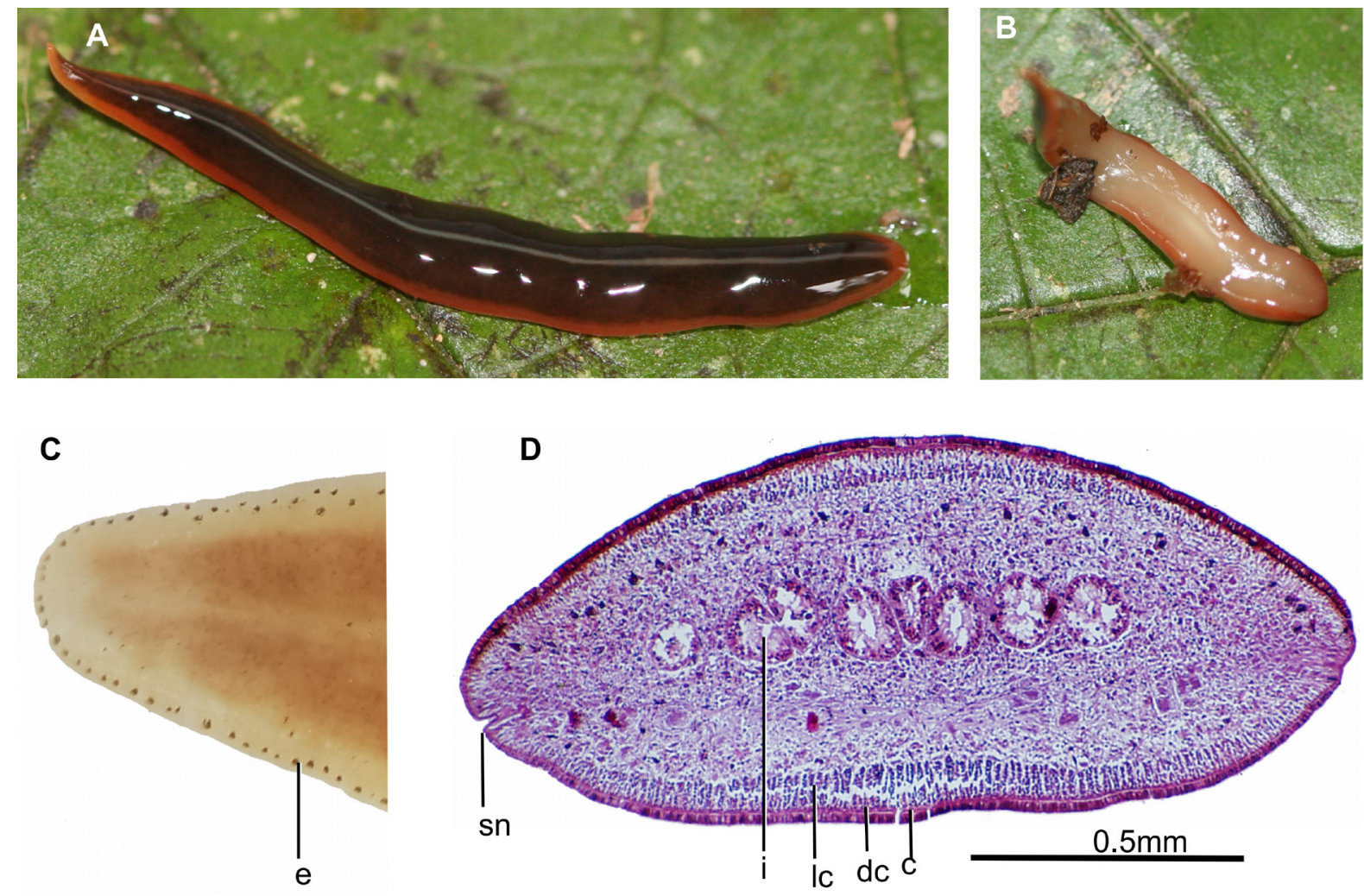

Fig. 6. Paraba tata Bolonhezi, Lago-Barcia \& Carbayo sp. nov. A. Dorsal view of living paratype F3151 (MZUSP PL2185). B. Ventral view of living paratype F3151. C. Anterior region of paratype F3768 (MZUSP PL2186) cleared in clove oil. D. Photomicrograph of a transverse section of the cephalic region of paratype F3151 showing the three typical layers of the cutaneous musculature and a sensory pit.
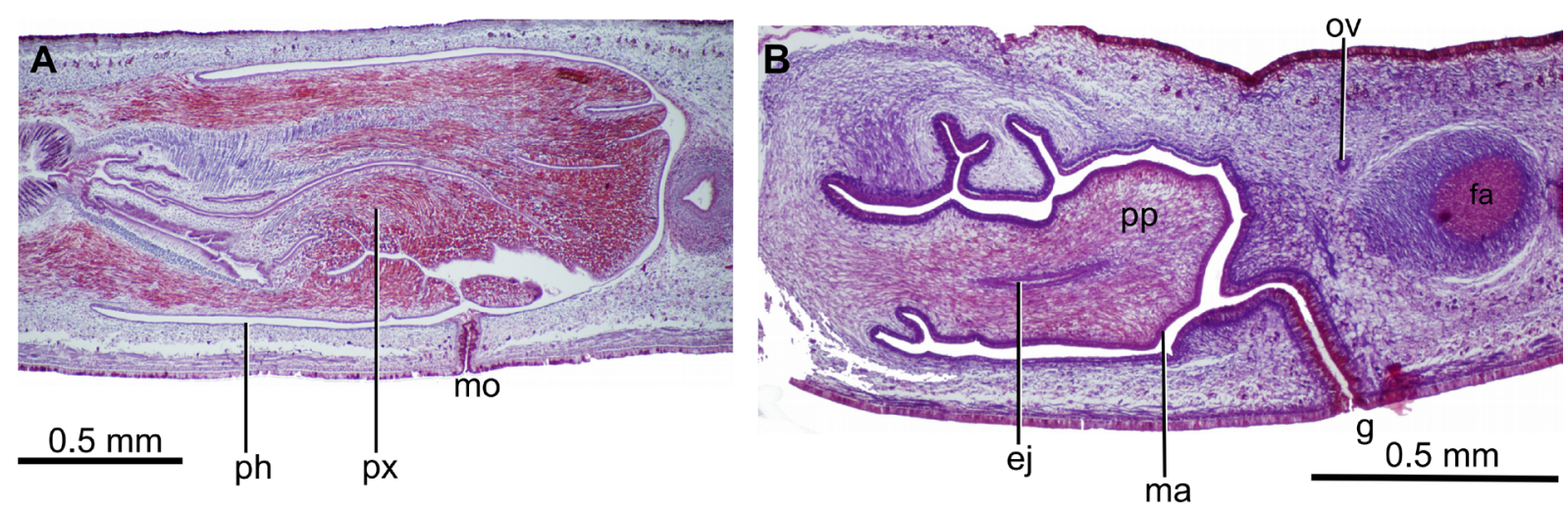

Fig. 7. Paraba tata Bolonhezi, Lago-Barcia \& Carbayo sp. nov. A. Photomicrograph of a sagittal section of the pharynx of the holotype (MZUSP PL2184). B. Photomicrograph of a sagittal section of the copulatory apparatus of specimen F3151 (MZUSP PL2185). 
The outer pharyngeal epithelium is underlain by a longitudinal muscle ( $3 \mu \mathrm{m}$ thick), and followed by a circular muscle ( $5 \mu \mathrm{m}$ thick). The inner pharyngeal epithelium is underlain by a subepithelial circular muscle ( $3 \mu \mathrm{m}$ thick) followed by a longitudinal muscle ( $50 \mu \mathrm{m}$ thick) with some fibers interspersed with the circular one (paratype F3151).

DORSAL TESTES. Located between the supraintestinal parenchymal muscle layer and the intestine. These testes extend from $1 \mathrm{~mm}$ behind the ovaries (28\% of body length) to shortly before the root of the pharynx. The sperm ducts run ventrally and curve medially to communicate with the respective lateral short branches of the extrabulbar prostatic vesicle (Figs 7B, 8). The prostatic vesicle is $320 \mu \mathrm{m}$ long, pear-shaped and horizontal; it is attached to the pharyngeal pouch. This vesicle is lined with a columnar, ciliated epithelium, which is pierced by necks of glands producing fine erythrophilic granules. The epithelium is surrounded by a tightly packed muscle $(150 \mu \mathrm{m}$ thick $)$ of fibers variously oriented. The ejaculatory duct is straight and runs through the penis papilla to open at its tip. This duct is lined with a cuboidal, ciliated epithelium, and is underlain by a circular muscle $(7 \mu \mathrm{m})$.

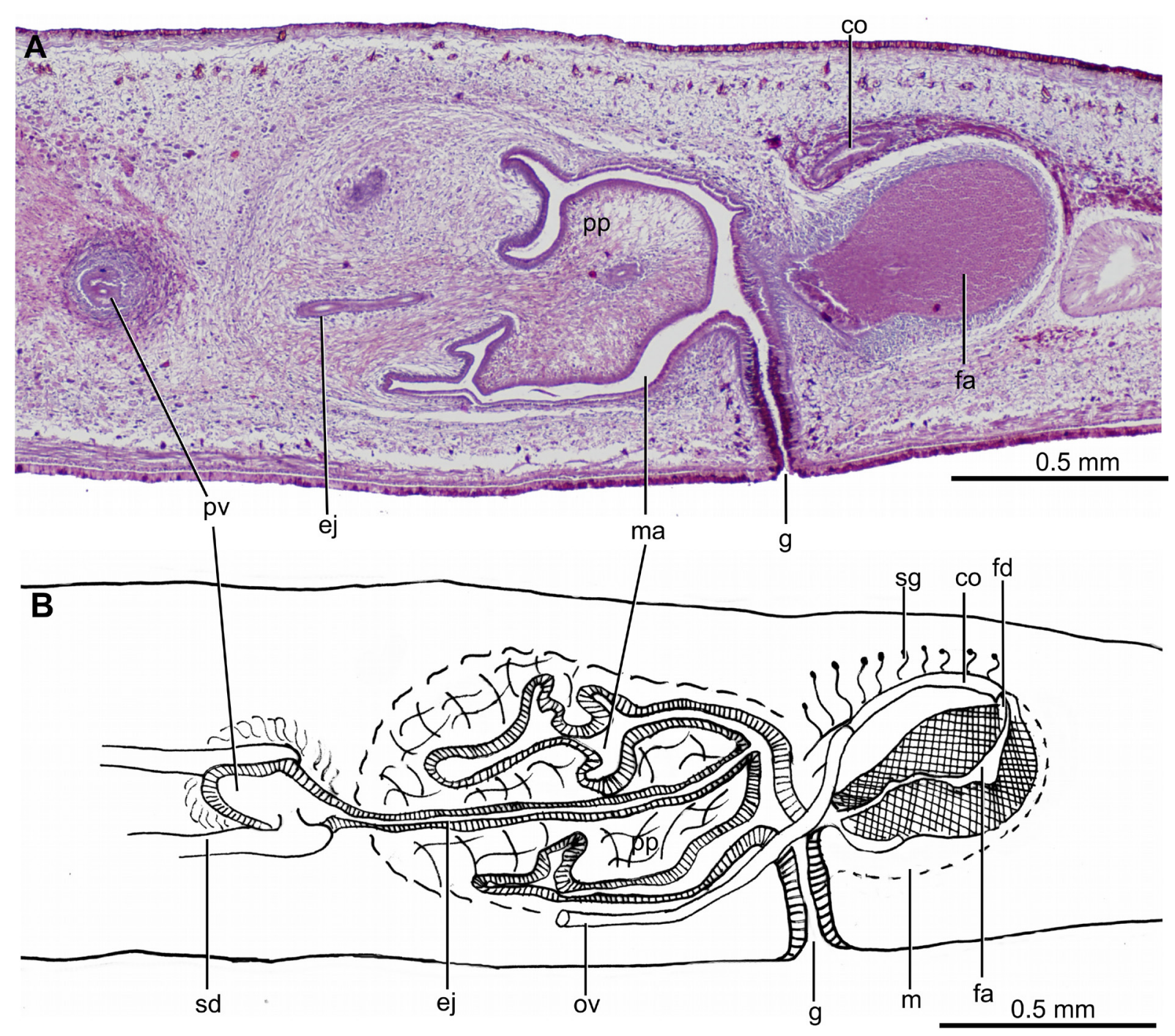

Fig. 8. Paraba tata Bolonhezi, Lago-Barcia \& Carbayo sp. nov., holotype (MZUSP PL2184). A. Photomicrograph of a sagittal section of the copulatory apparatus. B. Diagrammatic representation of the copulatory apparatus from sagittal sections. 
PeNIS PAPILLA. Cylindrical, somewhat irregular, with conical tip and dorsal insertion slightly anterior to the ventral one. It projects horizontally from the anterior wall of the male atrium (Figs 7B, 9A) and its posterior portion is slightly directed to the dorsal side. The penis papilla is lined with a cuboidal epithelium $11 \mu \mathrm{m}$ high. The subepithelial musculature of the penis papilla consists of a $7 \mu \mathrm{m}$ thick circular layer, followed by a longitudinal muscle $7 \mu \mathrm{m}$ thick. The epithelium of the penis papilla is pierced by necks of glands producing erythrophil granules. These glands are absent in the tip of the papilla; instead, necks of glands producing cyanophil granules pierce the epithelium of the tip. Additionally, necks of glands producing a dark reddish secretion pierce the entire papillar epithelium.

Male atrium. Exhibits a few dorsal folds. It is lined by a cuboidal, non-ciliated epithelium, which is underlain by a $7.5 \mu \mathrm{m}$ thick circular muscle, followed in its distal half by a $5 \mu \mathrm{m}$ thick longitudinal muscle. The dorso-anterior section of the male atrium receives necks of abundant glands producing fine cyanophil granules.

Ovaries. Ovoid, with a maximum diameter of $300 \mu \mathrm{m}$ (Fig. 9B). They are located between the subintestinal parenchymal muscle layer and the nerve plate, and lie at a distance from the anterior tip of the body equal to $23 \%$ of the body length (F3768). The ovovitelline ducts arise from the mid-dorsal region of the ovaries. Before the level of the gonopore, these ducts ascend to join dorsally to the anterior section of the female atrium, subsequently forming a $500 \mu \mathrm{m}$ long common glandular ovovitelline duct (paratype F2637) located above the female atrium (Fig. 8). The very distal ascending portion of the ovovitelline ducts receives shell glands (Fig. 8B). The long common glandular ovovitelline duct runs first postero-dorsally and subsequently ventrally to communicate with the female genital duct. This duct is a projection of the dorso-posterior wall of the female atrium.

Female atrium. Ovoid, with its anterior region narrowed (Fig. 8B). This atrium is occupied by an epithelium with a multilayered aspect with the exception of a narrow central passage. Two types of glands, producing cyanophil and erythrophil, respectively, discharge their contents into the female atrium. The female: male atrial length is approximately $2: 1$. The female atrium is underlain by a $75 \mu \mathrm{m}$ thick circular muscle.
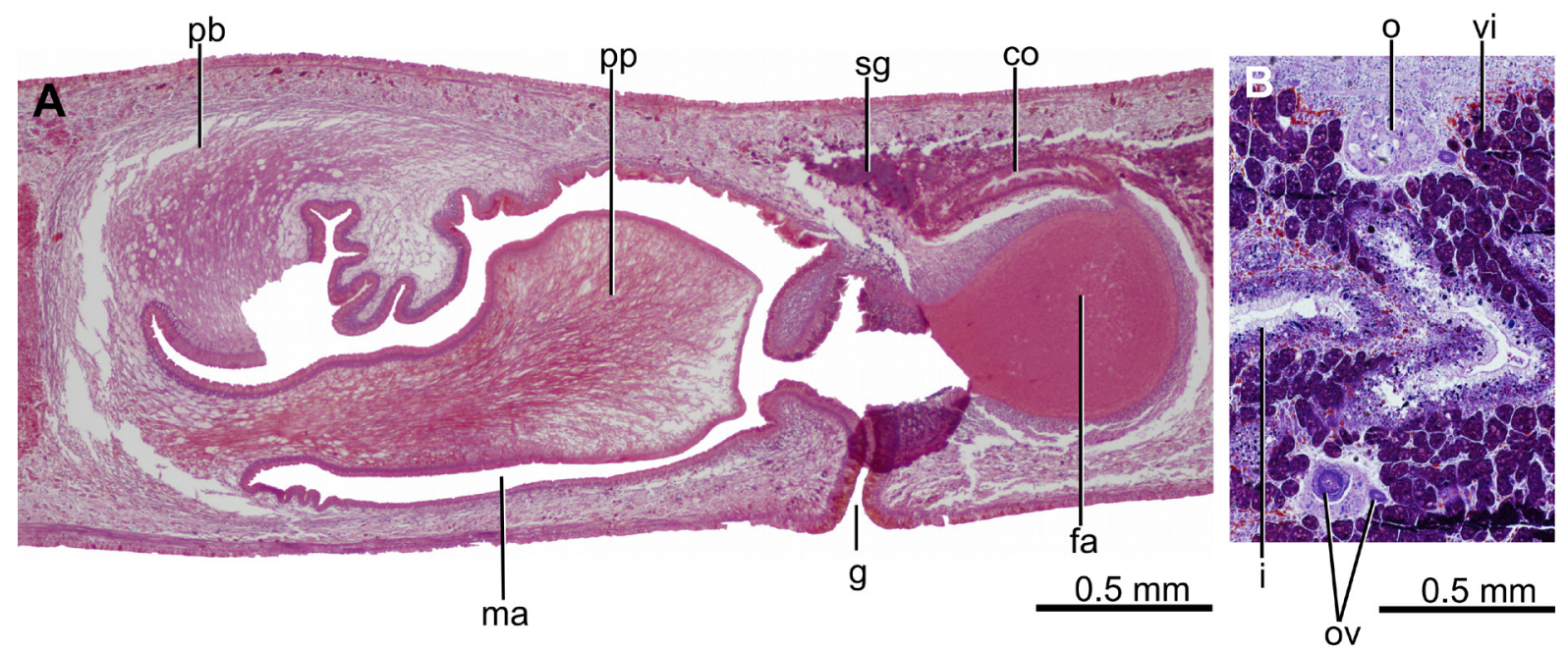

Fig. 9. Paraba tata Bolonhezi, Lago-Barcia \& Carbayo sp. nov. A. Photomicrograph of a sagittal section of the copulatory apparatus of the paratype F3768 (MZUSP PL2186). B. Photomicrograph of a transversal section of the ovaries region of the paratype F3768. 


\section{Remarks}

The new species fits the genus Paraba Carbayo et al., 2013, since it presents all of the diagnostic characters of the genus, except for some folds of the male atrium, which are present in the dorsal section of this species. However, other species of the genus also bear some folds in the male atrium, such as P. phocaica (Marcus, 1951), P. preta (Riester, 1938) and P. tingauna (Kishimoto \& Carbayo, 2012) (see Almeida et al. 2012). Folds may appear as a consequence of a contraction of the body at the time of fixation (Negrete et al. 2015). This might be the case, since the penis papilla of the species is also bent.

In its external aspect, Paraba tata sp. nov. resembles P. goettei (Schirch, 1929), P. franciscana (LealZanchet \& Carbayo, 2001) and P. incognita (Riester, 1938) in having a dark dorsum with a thin light midline. However, they differ in the details: the dorsum of $P$. goettei is a light brown color with pinkreddish body margins and a pink-reddish median line (vs dorsum dark orange-brown, orange body margins and a grey midstripe in the new species). Furthermore, $P$. goettei is $100 \mathrm{~mm}$ long (vs $22.5 \mathrm{~mm}$ in the new species) and its eyes are organised in two or more rows in the anterior portion of the body (vs one row in the new species). In turn, P. franciscana differs from P. tata sp. nov. in the dark gray color of the dorsum with a white median longitudinal stripe. Finally, $P$. incognita is different in the clear blue dorsal midline bordered by grayish blue paramedian stripes.

A similar general color pattern, dark dorsum with a thin light midline, can be found in two species of Pseudogeoplana, namely Ps. bonita (Schirch, 1929) and Ps. ehlersi (Graff, 1899). Nonetheless, they differ in the details as follows: the thin median line of Ps. bonita is yellowish with bottle green body margins (vs clear gray median stripe and orange body margins in the new species). Furthermore, the body margins of Ps. ehlersi do not differ from the dark general color of the dorsum and are not orange as in P. tata sp. nov.

In relation with the internal anatomy, eight species of the genus share with the new species the horizontal orientation of the prostatic vesicle and the female genital duct projected from the posterodorsal section of the female atrium, namely P. caapora (Froehlich, 1957), P. franciscana, P. gaucha (Froehlich, 1959), P. incognita, P. multicolor (Graff, 1899), P. rubidolineata (Baptista \& Leal-Zanchet, 2005), P. suva (Froehlich, 1959) and P. tingauna. Notwithstanding this, they differ in the details: in P. gaucha, P. rubidolineata, $P$. suva and $P$. tingauna the penis papilla is shorter than the male atrium (vs as long as the male atrium in the new species); in P. caapora, P. gaucha and P. multicolor the prostatic vesicle displays a conspicuous bifurcate portion (vs inconspicuous); in P. incognita and P. multicolor the copulatory apparatus is compact (vs relatively long); and in P. franciscana the posterior section of the female atrium is bent dorso-anteriorly (vs not bent).

\section{Distribution}

Only known from the type locality.

Piima Carbayo gen. nov. urn:1sid:zoobank.org:act:2D55638A-0EA8-4F57-A535-7FBB5F1AF802

\section{Type species}

Piima ata Carbayo gen. et sp. nov.

\section{Diagnosis}

A Geoplaninae with a small to medium-sized body, sub-cylindrical, slender with nearly parallel margins, anterior and posterior extremities rounded. Eyes and sensory pits surround the entire cephalic region. The eyes are monolobate and distributed along the body margins. The prostatic vesicle is extrabulbar 
and strongly muscularized. The penis papilla is cylindrical and horizontal. The distal half of the male atrium has large folds. The common glandular ovovitelline duct is dorsal to female atrium. A female genital cavity communicates between the common glandular ovovitelline duct with and the female atrium. The female atrium is long and well muscularized.

\section{Etymology}

The name 'Piima' is a composition of the Tupi (Indigenous Brazilian language) words 'pii' (meaning 'thin', 'slender') and 'ma' ('animal') (Tibiriçá 1984). It alludes to the body shape of the type species of the genus. The gender is female.

\section{Piima ata Carbayo gen. et sp. nov. urn:1sid:zoobank.org:act:835A8CB7-4F4E-485E-83D7-0FDF137290C3}

Figs $10-11$

Geoplana sp. 3 Carbayo et al., 2013

\section{Diagnosis}

A species of Piima gen. nov. with a black dorsum having a median white band and large white dots occasionally merged with each other; the copulatory is apparatus comparatively long; the muscularis of prostatic vesicle is extraordinarily strong; the penis papilla is finger-shaped; the male atrium has a distal, large traversed annular fold; the female genital duct is dilated and dorso-anteriorly flexed above the female atrium; the muscularis of the female atrium is very thick and dense.

\section{Etymology}

The name 'ata' ('atã') is a Tupi (indigenous Brazilian language) word meaning 'strong' (Tibiriçá 1984). It refers to the very thick muscle of the prostatic vesicle.

\section{Material examined}

\section{Holotype}

BRAZIL - 1 adult; State of São Paulo, São José do Barreiro, Parque Nacional da Serra da Bocaina; $22.75^{\circ} \mathrm{S}, 44.62^{\circ} \mathrm{W} ; 5$ Feb. 2008; F. Carbayo et al. leg.; transverse sections of cephalic region on 5 slides, sagittal sections of the ovarian region on 3 slides, horizontal sections of a portion behind ovarian region on 3 slides, transverse sections of pre-pharyngeal region on 4 slides, sagittal sections of pharynx and copulatory apparatus on 6 slides; field number F2027; MZUSP PL 1013.

\section{Paratype}

BRAZIL• subadult; same collection data as for holotype; 7 Sep. 2008; J. Pedroni et al. leg.; sagittal sections of pharynx and incipient copulatory apparatus on 2 slides; field number F2796; MZUSP PL 1194.

\section{Type locality}

Parque Nacional da Serra da Bocaina, São José do Barreiro, State of São Paulo, Brazil.

\section{Description}

MeAsurements. Living holotype is $30 \mathrm{~mm}$ in length and $3 \mathrm{~mm}$ in width.

BoDy. Slender, with parallel margins; the anterior is extremity rounded; the posterior extremity is pointed. The dorsal side is convex; the ventral one is flat; the body margins are rounded. The dorsal color is black 
and white (Fig. 10A). The anterior 10\% of the body exhibits a median black band separated from the black margins by a whitish area. Subsequently to this section, a pair of transverse black lines separated by a whitish band appears. From behind these black lines to the posterior end, the color is black except for a median white band ( $20 \%$ of the body width) and large white dots occasionally merged with each other. The ventral side is white, slightly gray in the first two millimeters of the body.

EYES. 30-50 $\mu \mathrm{m}$ in diameter, monolobated and lacking halos. These eyes are marginally located in a single row encircling the anterior region, and distributed in two-to-three irregular marginal rows until the posterior end of the body where they are scarce. The sensory pits are simple invaginations $30 \mu \mathrm{m}$ deep; and located ventro-marginally in a single row, from the very anterior end up to a portion equal to $30 \%$ of the body length. The relative mouth: body length is $61 \%$; the relative gonopore: body length is $77 \%$.

Epithelium. Ciliated only in the creeping sole, which is $74 \%$ of the body width in the pre-pharyngeal region. The ventral epithelium of the cephalic region is pierced by necks of numerous cells producing erythrophil granules. Besides rhabditogen cells, the dorsal and ventro-marginal epithelium of the prepharyngeal region is pierced by necks of two types of cells producing xanthophil and cyanophil granules, respectively, the latter also discharging their content through the ventral epithelium. A glandular margin is absent.

Cutaneous musculature. Consists of three muscle layers, namely a thin subepithelial layer $(2.5 \mu \mathrm{m}$ thick, dorsally and ventrally) of circular fibers, followed by a layer of decussate fibers $(2.5 \mu \mathrm{m}$ thick, dorsally and ventrally), and an innermost layer of longitudinal fibers ( $10 \mu \mathrm{m}$ dorsally, $18 \mu \mathrm{m}$ ventrally), arranged in loose bundles of 4-12 fibers each. The cutaneous musculature thickness relative to the body height is $7.4 \%$. There are three parenchymal muscle layers: a dorsal layer ( $3 \mu \mathrm{m}$ thick) of decussate fibers, a supraintestinal layer ( $30 \mu \mathrm{m}$ thick) of transverse fibers, and a subintestinal layer ( $25 \mu \mathrm{m}$ thick)
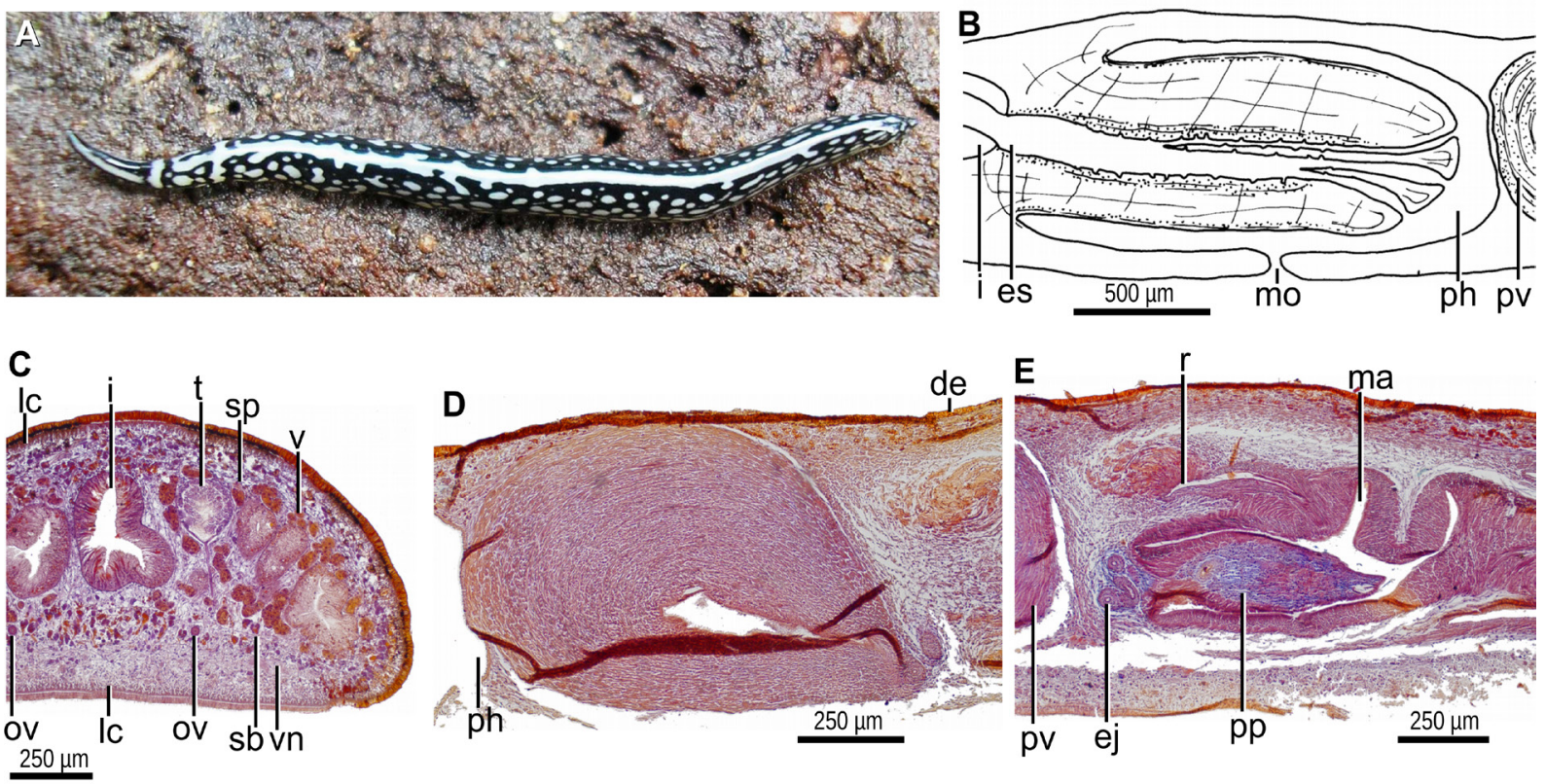

Fig. 10. Piima ata Carbayo gen. et sp. nov., holotype (MZUSP PL 1013). A. Dorsal view. B. Diagrammatic representation of the pharynx. C. Photomicrograph of a transverse section of the pre-pharyngeal region. D. Photomicrograph of a sagittal section of the prostatic vesicle. E. Photomicrograph of a sagittal section of penis papilla and the male atrium. 
of transverse fibers, lying above the ventral nerve plate. Towards the anterior end of the body, these layers become thinner and extinct.

Mouth. Lies about half way along the pocket (Fig. 10B). The pharynx is cylindrical, with its dorsal insertion slightly posteriorly located. An esophagus is inconspicuous. The outer pharyngeal epithelium is underlain by a one-fiber-thick longitudinal layer, followed by a two-fiber-thick circular one. The inner pharyngeal epithelium consists of a layer $(50 \mu \mathrm{m}$ thick) of circular fibers with some interspersed longitudinal fibers in its ectal portion.

ROUNDED TESTES. $200 \mu \mathrm{m}$ in diameter, located between the supraintestinal parenchymal muscle layer and the intestinal diverticula (Fig. 10C). They are arranged in a single row on each side of the body, and extend from shortly behind the level of the ovaries (equal to $21 \%$ of the body length) to closely to the root of the pharynx (equal to $56 \%$ of the body length). The efferent ducts are located between the
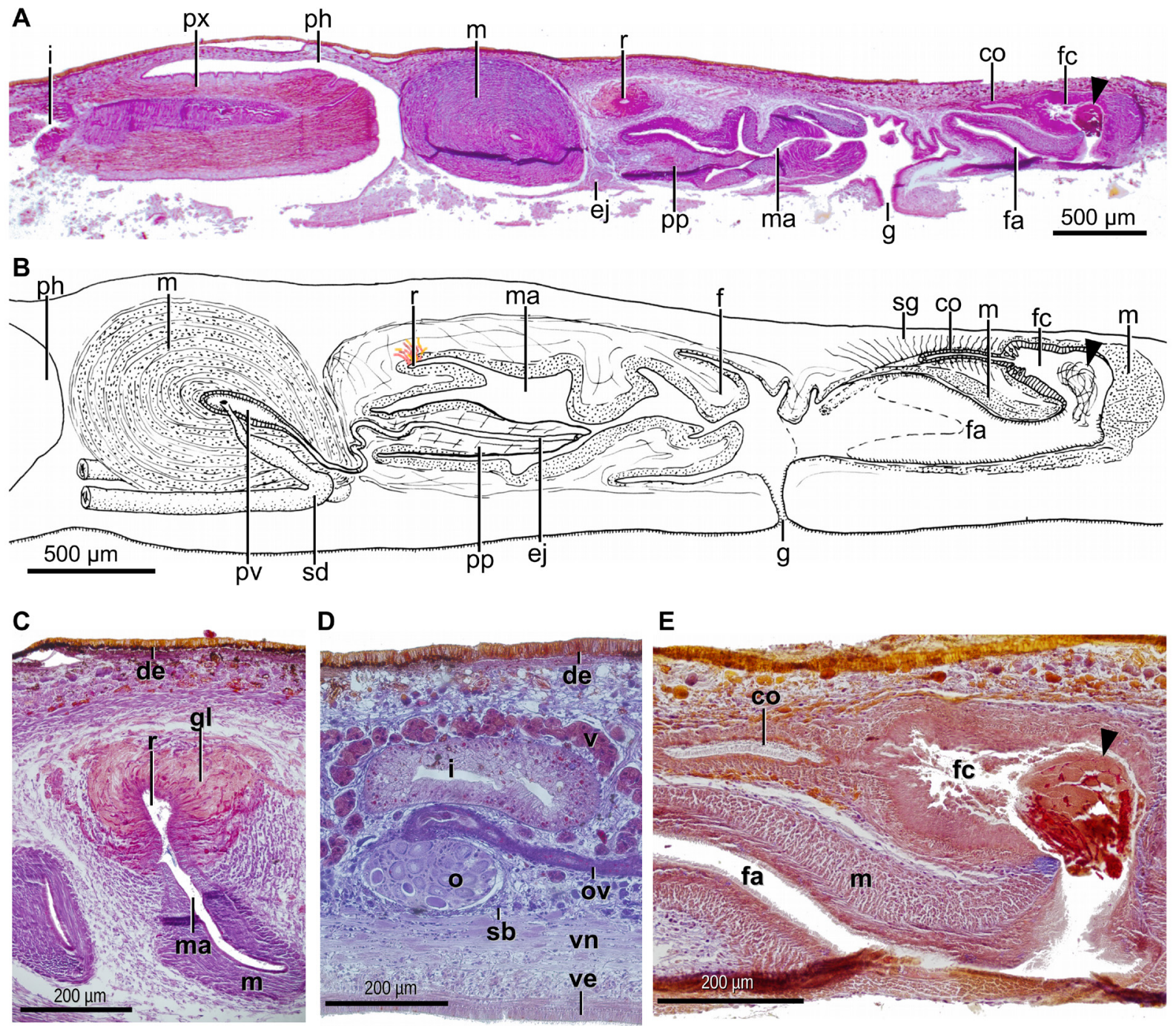

Fig. 11. Piima ata Carbayo gen. et sp. nov., holotype (MZUSP PL 1013). A. Photomicrograph of a sagittal section of the pharynx and copulatory apparatus. B. Diagrammatic representation of the copulatory apparatus. $\mathbf{C}-\mathbf{E}$. Photomicrographs of sagittal sections of the recess of the male atrium $(\mathbf{C})$, ovary $(\mathbf{D})$ and female genital cavity and female atrium $(\mathbf{E})$. 
fibers of the transverse subintestinal muscle layer. The distal portion of these ducts contains sperm and is dilated. Reaching the penis bulb, these ducts bend anteriorly to the sagittal plane and subsequently penetrate the antero-dorsal portion of the muscularis of the prostatic vesicle to open laterally into the anterior portion of the prostatic vesicle. The prostatic vesicle is elongate, narrower distally (Figs 10D, $11 \mathrm{~A}-\mathrm{B})$. This vesicle is straight and inclined postero-ventrally. The lining epithelium of the vesicle is cuboidal and ciliated. Cells producing fine erythrophil granules and scarce cells secreting cyanophil granules discharge their products through the epithelium into the vesicle. The muscularis of the prostatic vesicle is composed of an extremely dense and thick muscle (350 $\mu \mathrm{m}$ thick) of superposed layers of diagonal fibers. The vesicle communicates with the ejaculatory duct in the ventro-anterior section of the penis bulb. The proximal portion of the ejaculatory duct meanders towards the dorsal side; subsequently, it crosses the center of the penis papilla (Figs 10E, 11B). The ejaculatory duct is lined with a cuboidal, ciliated epithelium, and is underlain by a circular muscle, $20 \mu \mathrm{m}$ thick anteriorly, $5 \mu \mathrm{m}$ thick distally.

Penis PaPILLA. Close to its opening at the subapical tip, the ejaculatory duct widens slightly and the free surface of its lining epithelium is undulated and apparently not ciliated. The penis papilla is finger-shaped, with a conical tip, and horizontally positioned (Figs 10E, 11A-B). This papilla projects from the anteroventral section of the male atrium and is half as long as the male atrium. The penis papilla is lined with a squamous-to-cuboidal epithelium, which is pierced by necks of cells producing cyanophil granules. The epithelium of the distal half of the papilla is additionally crossed by necks of cells producing xanthophil granules. The muscularis of the penis papilla is composed of a subepithelial circular muscle followed by a longitudinal muscle. These layers are dense and thick ( $25 \mu \mathrm{m}$ and $15 \mu \mathrm{m}$ each) in the proximal section of the papilla, but inconspicuous distally.

Male atrium. Elongate and divided into two halves. The anterior half houses the penis papilla and is relatively smooth (Fig. 11A-B). Dorsal to the penis papilla, the male atrium possesses a recess (Fig. 11BC). The distal half is narrower and provided with a large, transverse annular fold. The lining epithelium of the male atrium is squamous-to-cuboidal, and is crossed by necks of cells producing granules with a weak affinity for a cyanophil stain. In its bottom, the dorsal recess receives xanthophil granules produced by numerous cells; in its distal section, the recess receives eryhtrophil granules (Fig. 11C). The muscularis of the male atrium is strong, and composed of a dense subepithelial circular muscle, followed by a longitudinal one; the thickness of these muscles becomes highest in the midregion, 100 $\mu \mathrm{m}$ and $10 \mu \mathrm{m}$, respectively. A muscle coat of decussate fibers envelopes the male atrium.

Ovaries. The vitellaria are well developed. The ovaries, ovoid, are $200 \mu \mathrm{m}$ in length and $150 \mu \mathrm{m}$ in diameter. They are ventrally located between the intestine and the subintestinal parenchymal muscle layer (Fig. 11D). They are located at a distance from the anterior extremity of the body equal to $20 \%$ of the body length. The ovovitelline ducts arise from the dorso-lateral aspect of the ovaries. The proximal portion of these ducts is slightly dilated and contains spermatozoa. These ducts run ventrally to the sperm ducts, between the fibers of the subintestinal parenchymal muscle layer. Reaching the region of the gonopore, they bend obliquely to the sagittal plane and subsequently join to communicate with the common glandular ovovitelline duct, the latter located dorsally to the female atrium (Fig. 11B, E). The ovovitelline ducts are surrounded by a decussate muscle. The distal portion of these ducts receives shell glands. The common ovovitelline duct is long, horizontally placed, and surrounded by a decussate muscle $8-15 \mu \mathrm{m}$ thick. The common ovovitelline duct connects with a short canal similar to this common duct but devoid of shell glands. In turn, this short canal opens into the anterior face of a dorsal, large and dilated female genital cavity. This cavity is located dorsally to the posterior region of the female atrium. The cavity contains a lump of a cyanophil granular mass attached to a strongly erythrophil secretion. The erythrophil secretion exhibits an amorphous aspect in some regions, while in others it is constituted of parallel strands (Fig. 11E). The female genital cavity is lined with an epithelium having a multilayered aspect and an irregular free surface; the epithelial portion nearest to 
the common ovovitelline duct exhibits gaps. The epithelial female genital cavity is crossed by necks of cells producing erythrophil granules, and its muscularis is composed of a circular muscle ( $9 \mu \mathrm{m}$ thick), followed by a thin longitudinal muscle. The female atrium is long and spacious; it is more dilated in its midregion. It is $75 \%$ as long as the male atrium.

Female ATRIUM. Lined with a cuboidal, ciliated epithelium; cilia are absent near the gonopore canal. The female atrial epithelium convergent with the female genital cavity is crossed by a conspicuous mass of necks of cells producing cyanophil secretion (Fig. 11E); the rest of the female atrial epithelium is pierced by necks of cells producing cyanophil granules, and by a second type of cells producing granules with a poor affinity for erythrophil stain. The epithelium of the female atrium is surrounded by a longitudinal muscle $(9 \mu \mathrm{m}$ thick), followed by a circular muscle (30-50 $\mu \mathrm{m}$ thick), the latter with some interspersed longitudinal fibers, and an ectal, thin longitudinal muscle. The circular layer surrounding the middorsal and posterior portion of the female atrium is very thick and dense, reaching up to $200 \mu \mathrm{m}$ (Fig. 11E). A muscle coat enveloping the female atrium is absent. The gonopore canal is lined by a columnar ciliated epithelium.

\section{Remarks}

This species is peculiar among the members of Geoplaninae and does not fit well any of the 24 current geoplanin genera (the collective genus Pseudogeoplana Ogren \& Kawakatsu, 1990 excluded). The species resembles more closely the diagnostic features of Paraba (Geoplaninae), in that the body is slender, the eyes are monolobate, the pharynx is cylindrical, the prostatic vesicle is extrabulbar, the penis papilla is protrusible, the ovovitelline ducts join each other above the female atrium, and the female atrium is clothed with an epithelium with a multilayered aspect (Carbayo et al. 2013). However, the copulatory apparatus is comparatively longer, the muscle of the prostatic vesicle is extraordinarily thick (vs thin), the male atrium presents a distal, large annular fold (vs not folded), the penis papilla is finger-shaped (vs conical) and in that there is no female genital duct but a dilated genital cavity projected forwards over the female atrium. This combination of features is unique among all members of Geoplaninae and leads to the proposal of a new genus for it. In favor of this proposal are the ambiguous phylogenetic affinities of the species to other Geoplaninae species, as inferred from molecular data (see Carbayo et al. 2013). None of the molecular analyses placed the new species within, or sister to, the clade constituted by the type species of Paraba (i.e., P. multicolor (Graff, 1899)) and other members of this genus. The Bayesian Inference (BI) (Carbayo et al. 2013, fig. S2B) analysis positioned the new species as a sister species of $P$. phocaica with a high posterior probability, whereas the Maximum Likelihood (ML) (Carbayo et al. 2013, fig. 3) analysis shows a low support for this clade. The Maximum Parsimony (MP) analysis revealed this species as sister to a large group including members of several genera, none of them members of Paraba. Therefore, the molecular approach indicates that Piima ata sp. nov. does not show a close relationship to any of the genera, nor do the morphological attributes support the membership of these species to any of the current genera. For this reason, a new genus is proposed for this species.

\section{Distribution}

Only known from the type locality.

\section{Discussion}

The three new species and the new genus are an additional contribution to the knowledge of the morphological and taxonomic richness of land flatworms of the Atlantic forest. Paraba tata sp. nov. fits well the genus in that its morphology compares well with the diagnostic features of the genus. In turn, Obama apiguara sp. nov. deviates from its congeners in that the eyes of this species are only monolobate and the penis papilla is provided with a small intra-papillar papilla. Furthermore, O. apiguara sp. nov. 
bears glandular fossae opening through the epidermic epithelium, a structure unknown in any other land planarian. Piima ata gen. et sp. nov. also presents unique features among Geoplaninae. Thus far, molecular markers have failed to reveal phylogenetic affinities of this species with other taxa (Carbayo et al. 2013). Perhaps additional molecular markers or Next-Generation Sequencing (Álvarez-Presas \& Riutort 2014), would give us a better understanding of the taxonomic affinities of this new species and genus.

\section{Acknowledgments}

We are grateful to the Instituto Chico Mendes de Conservação da Biodiversidade-ICMBIO (Proc. 117484 and 57798-1) and the Instituto Florestal de SP (42.520/2007) for licensing the field work. We also thank Ana Paula Araujo, Cláudia Olivares, Débora Redivo, Júlio Pedroni, Leonardo Zerbone, Marcos Santos Silva, Marília Jucá, Welton Araújo (EACH, USP) for assistance during the sampling. Thanks are due to Geison Castro da Silveira and Lucas Beltrami (EACH, USP) for histological processing. KGO thanks CNPq, and LBB USP for undergraduate fellowships. ALA thanks CAPES, and DLB CNPq for PhD fellowships. FC has financial support from FAPESP (Proc. 2019/12357-7).

\section{References}

Almeida A.L., Kishimoto R.G. \& Carbayo F. 2012. Two new land planarian species (Platyhelminthes: Tricladida) from the Brazilian Atlantic Forest. Zoologia 29 (5): 430-438.

https://doi.org/10.1590/S1984-46702012000500006

Álvarez-Presas M. \& Riutort M. 2014. Planarian (Platyhelminthes, Tricladida) diversity and molecular markers: a new view of an old group. Diversity 6: 323-338. https://doi.org/10.3390/d6020323

Bueno F.S. 1998. Vocabulário tupi-guarani português. Éfeta Editora, São Paulo.

Carbayo F. 2019. Planárias Terrestres Neotropicais - Uma Base de dados sobre os tricládidos. http://planarias.each.usp.br/filtrar/caracteristica [accessed 3 Dec. 2019].

Carbayo F., Álvarez-Presas M., Olivares C.T., Marques F.P.L., Froehlich E.M. \& Riutort M. 2013. Molecular phylogeny of Geoplaninae (Platyhelminthes) challenges current classification: proposal of taxonomic actions. Zoologica Scripta 42: 508-828. https://doi.org/10.1111/zsc.12019

Cason J.E. 1950. A rapid one-step Mallory-Heidenhain stain for connective tissue. Stain Technology 25 (4): 225-226. https://doi.org/10.3109/10520295009110996

Froehlich C.G. 1956. Tricladida Terricola das regiões de Teresópolis e Ubatuba. Papéis Avulsos do Departamento de Zoologia 12 (16): 313-344.

Marcus E. 1951. Turbellaria brasileiros (9). Boletim da Faculdade de Filosofia, Ciências e Letras da Universidade de São Paulo, Série Zoologia 6: 5-215.

https://doi.org/10.11606/issn.2526-4877.bsffclzoologia.1951.125221.

Negrete L., Leal-Zanchet A.M. \& Brusa F. 2015. A new species of Notogynaphallia (Platyhelminthes, Geoplanidae) extends the known distribution of land planarians in Chacoan province (Chacoan subregion) South America. Zoological Studies 54 (58): 1-14. https://doi.org/10.1186/s40555-015-0136-5

Sluys R. 1999. Global diversity of land planarians (Platyhelminthes, Tricladida, Terricola): a new indicator-taxon in biodiversity and conservation studies. Biodiversity and Conservation 8: 1663-1681. https://doi.org/10.1023/A:1008994925673

Tibiriçá L.C. 1984. Dicionário Tupi-Português. Traço Editora e Distribuidora, São Paulo. 
Manuscript received: 5 December 2019

Manuscript accepted: 10 June 2020

Published on: 20 August 2020

Topic editor: Rudy Jocqué

Desk editor: Marianne Salaün

Printed versions of all papers are also deposited in the libraries of the institutes that are members of the EJT consortium: Muséum national d'Histoire naturelle, Paris, France; Botanic Garden Meise, Belgium; Royal Museum for Central Africa, Tervuren, Belgium; Royal Belgian Institute of Natural Sciences, Brussels, Belgium; Natural History Museum of Denmark, Copenhagen, Denmark; Naturalis Biodiversity Center, Leiden, the Netherlands; Museo Nacional de Ciencias Naturales-CSIC, Madrid, Spain; Real Jardín Botánico de Madrid CSIC, Spain; Zoological Research Museum Alexander Koenig, Bonn, Germany; National Museum, Prague, Czech Republic. 